University of Nebraska - Lincoln

DigitalCommons@University of Nebraska - Lincoln

May 1984

\title{
Temperature-dependent resistivity of highly disordered Ni-Cr-Al alloys
}

R. Hight

Dale Electronics Corporation, Norfolk, Nebraska

C. Plough

Dale Electronics Corporation, Norfolk, Nebraska

David J. Sellmyer

University of Nebraska-Lincoln, dsellmyer@unl.edu

Follow this and additional works at: https://digitalcommons.unl.edu/physicssellmyer

Part of the Physics Commons

Hight, R.; Plough, C.; and Sellmyer, David J., "Temperature-dependent resistivity of highly disordered Ni-CrAl alloys " (1984). David Sellmyer Publications. 153.

https://digitalcommons.unl.edu/physicssellmyer/153

This Article is brought to you for free and open access by the Research Papers in Physics and Astronomy at DigitalCommons@University of Nebraska - Lincoln. It has been accepted for inclusion in David Sellmyer Publications by an authorized administrator of DigitalCommons@University of Nebraska - Lincoln. 


\title{
Brief Reports
}

Brief Reports are short papers which report on completed research which, while meeting the usual Physical Review standards of scientific quality, does not warrant a regular article. (Addenda to papers previously published in the Physical Review by the same authors are included in Brief Reports.) A Brief Report may be no longer than 31/2 printed pages and must be accompanied by an abstract. The same publication schedule as for regular articles is followed, and page proofs are sent to authors.

\section{Temperature-dependent resistivity of highly disordered $\mathrm{Ni}-\mathrm{Cr}$-Al alloys}

\author{
R. Hight and C. Plough \\ Dale Electronics Corporation, Norfolk, Nebraska 68701 \\ D. J. Sellmyer \\ Behlen Laboratory of Physics, University of Nebraska, Lincoln, Nebraska 68588
}

(Received 12 December 1983)

\begin{abstract}
Measurements are reported on the electrical resistivity of highly disordered $\mathrm{Ni}-\mathrm{Cr}$ - $\mathrm{Al}$ films between 4.2 and $300 \mathrm{~K}$. X-ray diffraction measurements show the films to be crystalline with a bcc structure. Negative temperature coefficients are observed and the resistivity data above about $50 \mathrm{~K}$ can be fitted by the expression $\rho(T)=\rho_{0}\left[1-c \ln \left(T^{2}+\Delta^{2}\right)\right]$, where $\Delta$ depends on the heat treatment of the sample.
\end{abstract}

The electrical resistance of highly disordered crystalline alloys and metallic glasses is a subject of considerable interest and diverse results. Positive (PTC) and negative (NTC) temperature coefficients of resistance, low-temperature resistance minima and maxima, and other transport anomalies are the rule rather than the exception. One of the most interesting phenomena discovered is the Mooij correlation in which highly resistive metals tend to have NTC when $\rho \geq 150 \mu \Omega \mathrm{cm}$, and PTC for smaller values of resistivity. ${ }^{1}$

Numerous models have been proposed to explain NTC and other anomalies in nonmagnetic alloys. These include the Ziman-Faber theory, ${ }^{2}$ a Kondo-type model based on electron scattering from two-level tunneling states, ${ }^{3}$ Mott $s-d$ scattering, ${ }^{4}$ theories which treat electron-phonon dynamics, ${ }^{5}$ a mechanism based on microscopic phase separation into regions of delocalized and weakly localized electron states, ${ }^{6}$ and theories based on Anderson localization or incipient localization. ${ }^{7}$ Critical discussion and reviews of these theories can be found in recent articles by Cote and Meisel, ${ }^{8}$ Carini, Nagel, Varga, and Schmidt ${ }^{9}$ and Girvin and Jonson. ${ }^{5}$

The purpose of this paper is to report the temperature dependence of resistivity for several films of approximate composition $\mathrm{Ni}_{29} \mathrm{Cr}_{32} \mathrm{Al}_{39}$. The films were prepared by magnetron sputtering and had a thickness of approximately 1000 $\AA$. X-ray diffraction scans were performed on films deposited on graphite under the same sputtering conditions. It was possible to index the Bragg reflections in terms of a bcc structure with lattice parameter $a=2.938 \pm 0.005 \AA$. This value of $\underline{a}$ is similar to that of $\beta^{\prime}-\mathrm{NiAl}(2.887 \AA)$ which has the ordered bcc structure. To measure the absolute resistivity of the material, films of thicknesses ranging from 〜 1000-5000 $\AA$ were prepared. The thicknesses of the films were measured with a Taly-surface profiler and some dependence of the resistivity on thickness was observed. An estimate of the resistivity of the material is $250 \pm 30 \mu \Omega \mathrm{cm}$. Figure 1 shows the resistance $R(T)$ for $\mathrm{Ni}_{29} \mathrm{Cr}_{32} \mathrm{Al}_{39}$ from 4.2 to $300 \mathrm{~K}$. The temperature coefficient of resistance is negative over the whole temperature region and there is a sharp upturn below about $15 \mathrm{~K}$. This lowtemperature upturn is likely due to a Kondo mechanism associated either with Ni-rich clusters containing a magnetic moment, or unwanted $3 d$ magnetic impurities, or both. The starting materials contained about 0.3 at. \% of $\mathrm{Fe}, \mathrm{Co}$, and Mn. We are not primarily interested in this feature. Although we have not measured the magnetic properties of our alloys, it is not likely that the NTC above about $50 \mathrm{~K}$ is due to magnetic scattering. This is so because $\mathrm{Ni}-\mathrm{Cr}$ alloys near the equiatomic composition exhibit PTC rather than

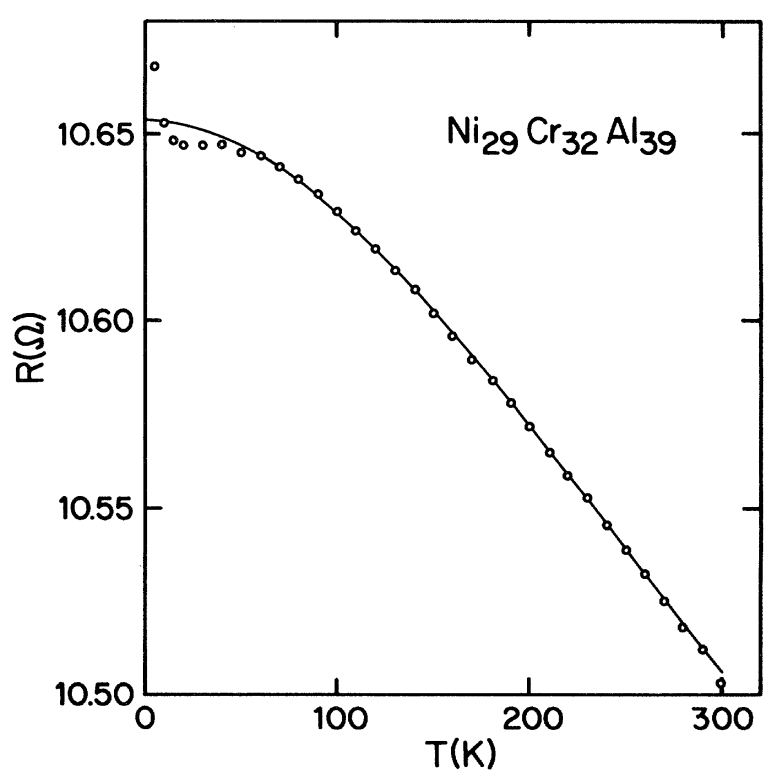

FIG. 1. Temperature dependence of the resistance of $\mathrm{Ni}_{29} \mathrm{Cr}_{32} \mathrm{Al}_{39}$ in the as-sputtered state. The curve represents a fit to Eq. (1) with the parameters given in the text. 
NTC. Adding Al to the level of about 40 at. $\%$ would not be expected to increase any tendency towards magnetic scattering. Thus the general character of $R(T)$ above about $50 \mathrm{~K}$, which looks to be of the form $1-(T / \theta)^{2}$ up to about $100 \mathrm{~K}$ and then tends towards a linear dependence, probably has a nonmagnetic origin. This character is often observed in metallic glasses and is usually explained by the ZimanFaber theories with $2 k_{f} \simeq q_{p}$, where $k_{F}$ is the Fermi wave vector and $q_{p}$ the position of the first peak in the x-ray intensity function. In our crystalline alloy it is not clear that such theories are applicable.

We have fitted the data to an expression derived from the two-level scattering model, based on the Kondo analogy. The result is

$$
R=R_{0}\left[1-c \ln \left(T^{2}+\Delta^{2}\right)\right] .
$$

The fit to this function is shown by the curve on the figure. Clearly, the fit is excellent with $c=0.01349$ and $\Delta=254 \mathrm{~K}$. An independently sputtered film also was measured and fitted to Eq. (1) to test for reproducibility. Essentially identical behavior was seen with $c=0.01256$ and $\Delta=251 \mathrm{~K}$. In order to test the sensitivity to possible structural modifications, a sample was annealed for $6 \mathrm{~h}$ at $340^{\circ} \mathrm{C}$. This decreased the resistivity by about $20 \%$. The resistance of this film is shown in Fig. 2. Again it is possible to fit the data with Eq. (1), but in this case $c=8.535 \times 10^{-3}$ and $\Delta=107$ $\mathrm{K}$. This significant change in $\Delta$ is consistent, at least, with the idea that excitations affected by structure may be significant.

The interpretation of these results is not entirely straightforward. Given that our samples are crystalline it appears that the original motivation for Eq. (1), which was based on the atomic tunneling model for glasses, is not applicable to our samples. However, it is not clear that a glassy structure is a requirement for the presence of a significant number of atoms capable of "two-level" tunneling. Tseui has suggested that any electronic interaction which leads to a scattering or quasilocalization of the electrons can give rise to a dependence like Eq. (1) ${ }^{3}$ and provides examples of fits to Eq. (1) in amorphous and crystalline alloys. Our results provide further support for the applicability of Eq. (1) to highresistivity crystalline alloys.

Recently, McLachlan has observed resistivity data with NTC in $\mathrm{TiO}_{x}$ metallic oxides. ${ }^{10}$ These data also could be fitted to Eq. (1) or Eq. (1) plus an electron-phonon scattering

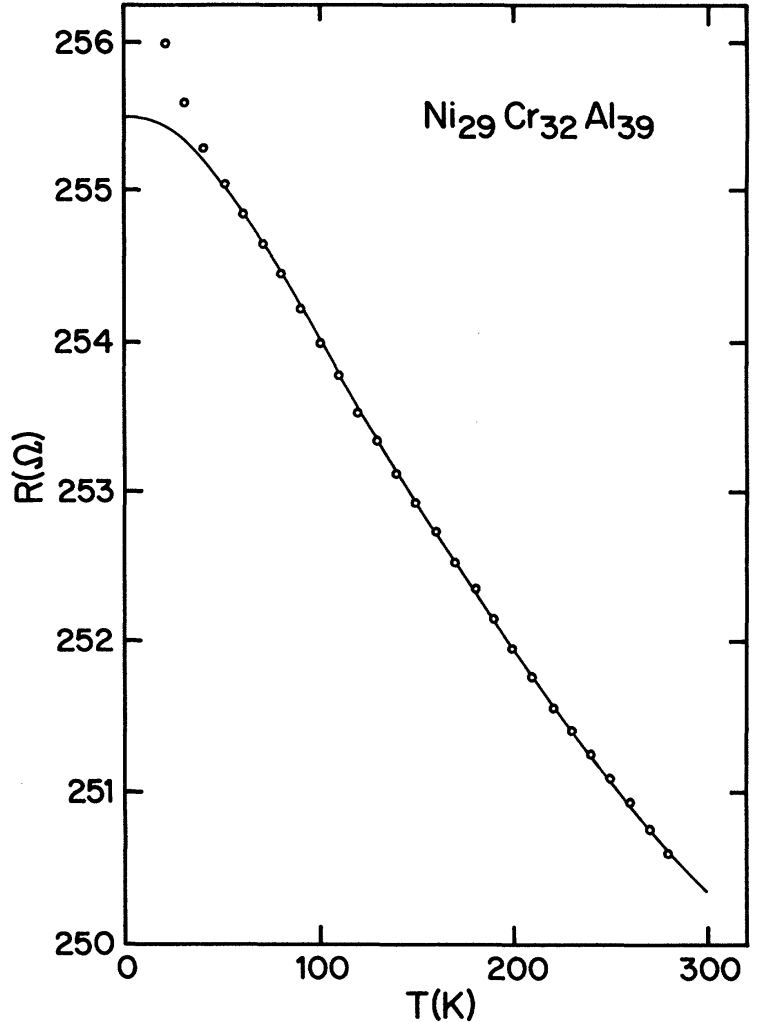

FIG. 2. Temperature dependence of the resistivity of $\mathrm{Ni}_{29} \mathrm{Cr}_{32} \mathrm{Al}_{39}$ after annealing for $6 \mathrm{~h}$ at $340^{\circ} \mathrm{C}$. The curve represents a fit to Eq. (1) with the parameters given in the text.

term. Although the oxides contain a large number of vacancies which can be thermally ordered and disordered, they represent yet another class of materials for which Eq. (1), along with its underlying basis, may be relevant.

In summary, the resistivity of our alloys supports the suggestion that a glassy metallic structure is not a necessary condition for the observation of the behavior predicted by Eq. (1). Rather, the data may provide additional support for suggestions of incipient electron localization operating either alone or in combination with electron-phonon interactions in highly disordered metals.
1J. H. Mooij, Phys. Status Solidi (a) 17, 521 (1973).

${ }^{2}$ T. E. Faber and J. M. Ziman, Philos. Mag. 11, 153 (1965).

${ }^{3}$ C. C. Tsuei, Solid State Commun. 27, 691 (1978).

${ }^{4}$ See N. F. Mott, Metal-Insulator Transitions (Taylor and Francis, New York, 1974).

5S. M. Girvin and M. Jonson, Phys. Rev. B 22, 3583 (1980).

6R. V. Aldridge, J. Phys. F 10,299 (1980).
${ }^{7}$ Y. Imry, Phys. Rev. Lett. 44, 469 (1980); J. Appl. Phys. 52, 1817 (1981); D. S. McLachlan, Solid State Commun. 42, 521 (1982).

8P. J. Cote and L. V. Meisel, in Glassy Metals I, edited by H. J. Guntherodt and H. Beck (Springer-Verlag, Berlin, 1981), p. 141.

9J. P. Carini, S. R. Nagel, L. K. Varga, and T. Schmidt, Phys. Rev. B 27, 7589 (1983).

10D. S. McLachlan, Phys. Rev. B $\underline{25}, 2285$ (1982). 